\title{
DESAIN JARINGAN RAWA DI WILAYAH KANTAN KECAMATAN PANDIH BATU KABUPATEN PULANG PISAU
}

\author{
Tahan \\ Program Studi Teknik Sipil, Fakultas Teknik, Universitas Kristen Palangka Raya \\ E-mail: utuntahan10@gmail.com/HP.081349160846
}

\begin{abstract}
ABSTRAK
Daerah rawa di Indonesia mempunyai lahan seluas 39.424.500 hektar.Jumlah rawa Pasang surut di Kabupaten Pulang Pisau 9.063.000 hektar, di Kecamatan Maliku 350.000 hektar. Daerah rawa di Pangkoh V dan VI dibangun pada Tahun 1983 meliputi jaringan drainase saluran primer sepanjang $27 \mathrm{~km}$ saluran Sekunder sepanjang $599 \mathrm{~km}$, dan selesai pada tahun 1985 dengan luas areal 9246 hektar. Pada tahun 1985 transmigrasi di datangkan dari luar kecamatan, Sebagian dari penduduk Kalimantan Tengah dengan tujuan memanfaatkan lahan rawa yang ada. Dengan kondisi saluran sekunder di Wilayah Kantan Kecamatan Pandih Batu Kabupaten Pulang Pisau. yang tidak berfungsi oleh sebab alih fungsi lahan pertanian, banyak jadi lahan perkebunan, masalahnya tingkat keasaman air masih tinggi, sehingga tanaman padi jadi tidak normal. Oleh karena itu perlu adanya desain jaringan rawa yaitu jaringan sekunder. Secara umum penelitian di lakukan dalam beberapa tahap,yaitu: pengumpuan data,analisis data, evaluasi kapasitas, dan desain sistem drainase. Jenis data yang dikumpulkan sebagai bahan analisis adalah data sekunder dan data primer. Data sekunder berupa peta, data curah hujan bulanan dan beberapa data lainnya. Disamping untuk analisis, data sekunder tersebut juga akan dijadikan pedoman dalam pengumpulan data primer. Data primer yang dikumpulkan anatara lain perhitungan curah hujan dengan cara normal, log normal, log pearson III, dan Gumbel. Dari perhitungan curah hujan data Gumbel yang paling akurat, sehingga dijadikan pedoman dalam perhitungan profil memanjang dan melintang saluran. Untuk menentukan debit drainase rencana (Qr) dan besaran kapasitas pengaliran drainase (Qs). Jika Qr > Qs akan dilakukan perencanaan ulang terhadap kapasitas pengaliran. Besarnya volume debit air pada sistem jaringan irigasi yang dialirkan melalui saluran sekunder umur rencana 5 tahun $(X \neg T R=5$ Tahun) dengan menggunakan distribusi probalitas Gumbel adalah 495,303 mm. Intensitas curah hujan 165,43 mm/jam.Menormalisasi kapasitas 122 saluran yang berfungsi dan perbaikan 28 saluran yang tidak berfungsi dengan ketinggiaan air 1,50 $\mathrm{m}$ untuk menghilangkan kadar asam tanah di sekitar 150 saluran sekunder. perhitungan saluran sekunder, diambil dari perencanaan debit aliran perhitungan yang terbesar yaitu $Q=22,40 \mathrm{~m} 3 / \mathrm{dt}>\mathrm{Qr}$ (Debit drainase rencana kumulatif $=16,21 \mathrm{~m} 3 / \mathrm{dt}$ ). Dimensi penampang pada 122 saluran sekunder dan perbaikan 28 saluran yang tidak berfungsi itu semua di normalisasi.
\end{abstract}

Kata Kunci : Desain, Jaringan Drainase, Metode, Analisa, Dimensi, Irigasi, Debit Air Dan Evaluasi

\begin{abstract}
Total about 39,424,500 hectares of swamp areas is found in Indonesia. The tidal swamparea in Pulang Pisau Regency is 9,063,000 hectares, and in Maliku District alone is 350,000hectares. The swamp areas in Pangkoh V and VI was firstly built in 1983 covering a $27 \mathrm{~km}$ longprimary drainage network and $599 \mathrm{~km}$ long secondary canals and then completed in 1985 withan area of 9,246 hectares. In 1985 transmigration was brought in from outside the sub-district,some of whom were residents of Central Kalimantan with the aim of exploiting the existingswamps. With the condition of the secondary channel in Kantan village, Pandih Batu sub-districtthat is not functioning as a result of the conversion of agricultural land into mining land, theproblem is that acid water is still high, so that rice plants become abnormal. Therefore it isnecessary to design a swamp network, namely a secondary network.Generally, the study was done out in several stages, namely: data collection, dataanalysis, capacity evaluation, and drainage system design. The types of data collected as materialfor analysis are secondary data and primary data. Secondary data are maps, monthly rainfall dataand several other data. In addition to
\end{abstract}


analysis, secondary data will also be used as a guide inprimary data collection. Primary data that will be collected include the calculation of rainfall in the normal way, normal log, Pearson III log, and Gumbel. From the calculation of rainfall the Gumbel data is the most accurate, so that it is used as a guide in calculating the longitudinal and transverse profiles of the channel. To determine the planned drainage discharge $(Q r)$ and theamount of drainage capacity $(Q s)$. If $Q r>Q s$ will be redesigned the flow capacity.The amount of water discharge volume in the drainage network system that is flowedthrough the general secondary channel of the 5-year plan (XTR $=5$ years) using the Gumbelprobability distribution is $495.303 \mathrm{~mm}$, the rainfall intensity is $165.43 \mathrm{~mm} / \mathrm{hour}$. Normalizingthe capacity of 22 functioning channels and repairing 28 non-functioning channels with a waterlevel of $1.50 \mathrm{~m}$ to remove acidic levels of groundwater in around 150 secondary channels. Thecalculation of the secondary channel is taken from the largest calculated flow rate plan, namely $Q$ $=22.40 \mathrm{~m} 3 / \mathrm{s}>\mathrm{Qr}$ (cumulative plan discharge $=16.21 \mathrm{~m} 3 / \mathrm{s}$ ). The sectional dimensions of the 122 secondary channels and the repair of 22 channels are all needed to normalize.

Keywords: design, drainage network, method, analysis, dimensions, irrigation, water volume and evaluation.

\section{PENDAHULUAN}

Daerah rawa di Indonesia mempunyai lahan seluas 39.424.500 hektar. Selama ini tidak difungsikan sebagai pertanian dan perkebunan untuk kemajuan Ekonomi dan kemakmuran bangsa dan sekaligus mengurangi penganggura. Jumlah rawa pasang surut di Kabupaten Pulang Pisau 9.063.000 hektar, di Kecamatan Maliku 350.000 hektar. Daerah rawa di Pangkoh V dan VI dibangun pada Tahun 1983 meliputi jaringan rawa saluran primer sepanjang $27 \mathrm{~km}$ saluran Sekunder sepanjang $599 \mathrm{~km}$, dan selesai pada tahun 1995 dengan luas areal 9.246 hektar. Pada tahun 1995 transmigrasi didatangkan dari luar kecamatan, Sebagian dari penduduk Kalimantan Tengah dengan tujuan memanfaatkan lahan rawa yang ada. Dengan kondisi saluran sekunder di Wilayah Kantan Kecamatan Pandih Batu Kabupaten Pulang Pisau. yang tidak berfungsi oleh sebab alih fungsi lahan pertanian, banyak jadi lahan perkebunan, masalahnya tingkat keasaman air masih tinggi, sehingga tanaman padi jadi tidak normal. Oleh karena itu perlu adanya desain jaringan rawa yaitu jaringan sekunder.

\section{METODE PENELITIAN}

Secara umum penelitian dilakukan dalam beberapa tahap, yaitu: pengumpulan data, analisis data, evaluasi kapasitas, dan desain sistem drainase. Jenis data yang dikumpulkan sebagai bahan analisis adalah data sekunder dan data primer. Data sekunder berupa hasil studi terdahulu yangterdiri dari peta, dan data curah hujan. Di samping untuk analisis, sebagian dari data sekunder tersebut juga akan dijadikan pedoman dalam pengumpulan data primer. Data primer yang dikumpulkan antara lain profil memanjang dan melintang saluran, dan kondisi sistem drainase.Analisis data antara lain dimaksudkan untuk mendapatkan besran debit drainase rencana (Qr) dan besaran kapasitas pengaliran drainase (Qs). Kemudian dilakukan perbandingan Qr dan Qs untuk mengetahui kapasitas pengaliran. Jika Qr> Qs, akan dilakukan perencanaan ulang terhadap kapasitas pengaliran. Data sekunder. Data curah hujan diambi mulai tahun 2015-2019 dari daerah pengamat Unit Talio Kecamatan Pandih Batu Kabupaten Pulang Pisau.Peta yang diperlukan yaitu peta kawasan penelitian di Wilayah Kantan Kecamatan Pandih Batu, Kabupaten Pulang Pisau. Data primer dikumpulkan untuk melengkapi data yang tidak bisa Sepenuhnya diproleh melalui data sekunder dan untuk memperoleh gambaran yang lebih nyata di lapangan. Data primer yang dikumpulkan meliputi survey lokasi/daerah rawa, pengukuran jaringan rawa, survey pemetaan, dan survey kondisi tanah.

Cara pengumpulan data tersebut dilakukan dengan pengukuran lapangan dan panduan peta-peta sekunder. Alat ukur yang digunkan yaitu Theodolit. Pada tahap analisis data dilakukan beberapa kegiatan yaitu: Pemetaan dan penggambaran hasil pengukuran lapangan, perhitungan debit drainase dan perhitungan kapasitas drainase. Data hasil pengukuran lapangan selanjutnya diplot dan digambar 
dengan skala tertentu untuk mendapatkan peta situasi, profil memanjang dan melintang saluran drainase. Debit Drainase Rencana dihitung dengan metode Rasional. Tahapan Perhitungannya adalah sebagai berikut: Debit Curah Hujan $\left(\mathrm{Q}_{\mathrm{ah}}\right)$ Penentuan luas daerah aliiran saluran/tangkapan hujan. Luas tangkapan hujan untuk masing - masing saluran ditentukan dengan memperhatikan faktor topografi dan curahh hujan dominan aliran.Curah hujan rancangan. Curah hujan wilayah yang diperoleh dari data curah hujan harian maksimum tahunan selama 5 tahun terakhir dan berasal dari stasiun Maliku Kabupaten Pulang Pisau dan digunakan sebagai data dalam menghitung curah hujan rancangan. Distribusi probabilitas yang digunakan adalah distribusi Normal, Log Normal, Gumbel dan Log Pearson Type III. Curah hujan rancangan yang dihasilkan dengan distribusi Normal, log Normal, Gumbel dan Log Pearson Type III diuji kesesuaiannya dengan cara Chi-Kuadrat dan Smirnov-Kolmogorov (Triatmodjo, 2008). Keempat jenis distribusi yang diuji tersebut dipilih salah satu yang paling sesuai.

\section{HASIL DAN PERHITUNGAN}

Data curah hujan rencana adalah data curah hujan harian maksimum tahunan yang berasal dari stasiun 1 Talio Muara Kabupaten Pulang Pisau. Data tersebut merupakan data curah hujan dengan periode pengamatan 5 tahun terakhir, yaitu dari tahun 2015 - 2019. Data curah hujan maksimum tahunan tersebut dapat dilihat pada Tabel 1 berikut ini :

Tabel 1. Curah hujan Harian Maksimun Tahunan

\begin{tabular}{|c|c|c|}
\hline No. & Tahunan & Curah Hujan Maksimum (mm) \\
\hline 1 & 2015 & 156,4 \\
2 & 2016 & 206,6 \\
3 & 2017 & 200,0 \\
4 & 2018 & 615,6 \\
5 & 2019 & 89,60 \\
\hline
\end{tabular}

Sumber : BMG Palangka Raya

\section{Perhitungan Curah Hujan Rencana}

Langkah pertama dari hitungan adalah menghitung parameter statistik untuk menentukan jenis distribusi yang sesuai dengan data yang ada. Perhitungan Parameter Statistik dilakukan dalam beberapa Tabel dibawah ini.

Tabel 2. Hitungan Parameter Statistik

\begin{tabular}{|c|c|c|c|c|c|c|}
\hline No & Tahun & $\begin{array}{c}\text { Curah Hujan } \\
\mathrm{x},(\mathrm{mm})\end{array}$ & $(\mathrm{Xi}-\bar{X})$ & $(X i-\bar{X})^{2}$ & $(\mathrm{Xi}-\bar{X})^{3}$ & $(\mathrm{Xi}-\bar{X})^{4}$ \\
\hline 1 & 2015 & 156,4 & $-97,24$ & $9.455,62$ & $-919.464,50$ & 89.408 .728 \\
\hline 2 & 2016 & 206,6 & $-47,04$ & $2.212,76$ & $-104.088,23$ & $4.896 .310,34$ \\
\hline 3 & 2017 & 200,0 & $-53,64$ & $2.877,25$ & $-154.335,70$ & $8.278 .566,95$ \\
\hline 4 & 2018 & 615,6 & 361,96 & $131.015,1$ & $47.422 .225,6$ & 17.164.948.778,2 \\
\hline 5 & 2019 & 89,60 & $-164,04$ & $26.909,12$ & $-4.414 .172,04$ & 724.100 .781 \\
\hline \multicolumn{2}{|c|}{$\bar{\Sigma}$} & $1.268,20$ & $172.469,85$ & & $41.830 .165,1$ & 17.991 .633 .165 \\
\hline
\end{tabular}

Sumber: Hasil Perhitungan.

Tabel 3. Hitungan Parameter Statistik untuk Distribusi Log Normal dan Log Pearson III

\begin{tabular}{|c|c|c|c|c|c|}
\hline No & Tahun & $\mathrm{X},(\mathrm{mm})$ & $\log X$, & $\left(\log X_{i}-\overline{\log X}\right)^{2}$ & $\left(\log X_{i}-\overline{\log X}\right)^{3}$ \\
\hline 1 & 2015 & 156,4 & 2,194 & 0,0136 & $-0,0016$ \\
\hline 2 & 2016 & 206,6 & 2,315 & 0,0000 & 0,0000 \\
\hline 3 & 2017 & 200,0 & 2,301 & 0,0000 & 0,0000 \\
\hline 4 & 2018 & 615,6 & 2,790 & 0,2300 & 0,1103 \\
\hline 5 & 2019 & 89,60 & 1,952 & 0,1290 & $-0,0460$ \\
\hline \multicolumn{3}{|c|}{$\sum$} & 11,552 & 0,3726 & 0,06266 \\
\hline
\end{tabular}

Sumber: Hasil Perhitungan. 
Tabel 4. Perhitungan Perhitungan Nilai $x^{2}$ untuk Distribusi Normal

\begin{tabular}{|c|c|c|c|c|c|}
\hline Kelas & Interval & $\mathrm{E}_{\mathrm{f}}$ & $\mathrm{O}_{\mathrm{f}}$ & $\mathrm{O}_{\mathrm{f}}-\mathrm{E}_{\mathrm{f}}$ & $\frac{\left(O_{f}-O_{f}\right)^{2}}{E_{f}}$ \\
\hline 1 & $>428,07$ & 1 & 1 & 0 & 0 \\
\hline 2 & $305,55-428,07$ & 1 & 0 & 1 & 1 \\
\hline 3 & $201,73-305,55$ & 1 & 2 & -1 & 1 \\
\hline 4 & $79,214-201,73$ & 1 & 1 & 0 & 0 \\
\hline 5 & $<79,214$ & 1 & 1 & 0 & 0 \\
\hline & $\sum$ & 5 & 5 & $x^{2}$ & 2 \\
\hline
\end{tabular}

Sumber : Hasil Perhitungan.

Tabel 5. Perhitungan Perhitungan Nilai $x^{2}$ untuk Distribusi Log Normal

\begin{tabular}{|c|c|c|c|c|c|}
\hline Kelas & Interval & $E_{f}$ & $\mathrm{O}_{\mathrm{f}}$ & $\mathrm{O}_{\mathrm{f}}-\mathrm{E}_{\mathrm{f}}$ & $\frac{\left(O_{f}-O_{f}\right)^{2}}{E_{f}}$ \\
\hline 1 & $>398,107$ & 1 & 1 & 0 & 0 \\
\hline 2 & $251,189-398,107$ & 1 & 1 & 0 & 0 \\
\hline 3 & $169,825-251,189$ & 1 & 1 & 0 & 0 \\
\hline 4 & $112,202-169,825$ & 1 & 1 & 0 & 0 \\
\hline 5 & $<112,202$ & 1 & 1 & 0 & 0 \\
\hline & $\sum$ & 5 & 5 & $x^{2}$ & 0 \\
\hline
\end{tabular}

Sumber : Hasil Perhitungan

Tabel 6. Perhitungan Perhitungan Nilai $x^{2}$ untuk Distribusi Gumbel

\begin{tabular}{|c|c|c|c|c|c|}
\hline Kelas & Interval & $E_{f}$ & $\mathrm{O}_{\mathrm{f}}$ & $\mathrm{O}_{\mathrm{f}}-\mathrm{E}_{\mathrm{f}}$ & $\frac{\left(O_{f}-O_{f}\right)^{2}}{E_{f}}$ \\
\hline 1 & $>495,303$ & 1 & 1 & 0 & 0 \\
\hline 2 & $299,531-495,303$ & 1 & 1 & 0 & 0 \\
\hline 3 & $162,170-299,531$ & 1 & 1 & 0 & 0 \\
\hline 4 & $28,236-162,170$ & 1 & 2 & -1 & 1 \\
\hline 5 & $<28,236$ & 1 & 0 & 1 & 1 \\
\hline & $\sum$ & 5 & 5 & $x^{2}$ & 2 \\
\hline
\end{tabular}

Sumber : Hasil Perhitungan.

Tabel 7. Perhitungan Perhitungan Nilai $x^{2}$ untuk Distribusi Log Pearson III

\begin{tabular}{|c|c|c|c|c|c|}
\hline Kelas & Interval & $\mathrm{E}_{\mathrm{f}}$ & $\mathrm{O}_{\mathrm{f}}$ & $\mathrm{O}_{\mathrm{f}}-\mathrm{E}_{\mathrm{f}}$ & $\frac{\left(O_{f}-O_{f}\right)^{2}}{E_{f}}$ \\
\hline 1 & $>398,120$ & & & & 0 \\
\hline 2 & $251,190-398,120$ & 1 & 1 & 0 & 0 \\
\hline 3 & $199,530-251,190$ & 1 & 1 & 0 & 0 \\
\hline 4 & $79,433-199,530$ & 1 & 0 & 1 & 1 \\
\hline 5 & $<79,433$ & 1 & 2 & -1 & 2 \\
\hline & $\sum$ & 5 & 5 & $x^{2}$ & 0 \\
\hline
\end{tabular}


Tabel 8. Uji Smirnov - Kolmogorov Terhadap Distribusi Normal. Log Normal, Gumbel dan Log Pearson Type III

\begin{tabular}{|c|c|c|c|c|c|c|c|c|c|c|}
\hline \multirow[b]{2}{*}{ No } & \multirow[b]{2}{*}{$\begin{array}{l}\text { Curah } \\
\text { Hujan }\end{array}$} & \multirow[b]{2}{*}{$\mathrm{P}_{(\mathrm{E})} \%$} & \multicolumn{2}{|c|}{ Normal } & \multicolumn{2}{|c|}{ Log Normal } & \multicolumn{2}{|c|}{ Gumbel } & \multicolumn{2}{|c|}{ Log Pearson III } \\
\hline & & & $\begin{array}{l}\mathrm{P}_{(\mathrm{T})} \\
(\%)\end{array}$ & $\begin{array}{l}\Delta \\
(\%)\end{array}$ & $\begin{array}{l}\mathrm{P}_{(\mathrm{T})} \\
(\%)\end{array}$ & $\begin{array}{l}\Delta \\
(\%)\end{array}$ & $\begin{array}{l}\mathrm{P}_{(\mathrm{T})} \\
(\%)\end{array}$ & $\begin{array}{l}\Delta \\
(\%)\end{array}$ & $\begin{array}{l}\mathrm{P}_{(\mathrm{T})} \\
(\%)\end{array}$ & $\begin{array}{l}\Delta \\
(\%)\end{array}$ \\
\hline 1 & 89,60 & 16,6667 & 84,0 & 5,60 & 95,00 & 5,40 & 55,00 & 34,60 & 95,0 & 5,40 \\
\hline 2 & 156,4 & 33,3333 & 137,0 & 19,40 & 140,0 & 16,40 & 145,0 & 11,40 & 140,0 & 16,40 \\
\hline 3 & 200,0 & 50,0000 & 181,0 & 19,00 & 185,0 & 15,00 & 230,0 & 30,00 & 185,0 & 15,00 \\
\hline 4 & 206,6 & 66,6667 & 225,0 & 18,40 & 220,0 & 13,40 & 325,0 & 118,4 & 220,0 & 13,40 \\
\hline 5 & 615,6 & 83,3333 & 282,0 & 333,6 & 245,0 & 370,6 & 470,0 & 145,6 & 245,0 & 370,6 \\
\hline \multicolumn{3}{|c|}{$\Delta$ maks } & \multicolumn{2}{|c|}{$\begin{aligned} & \frac{333,6}{615,6} \times 100 \% \\
= & 54,2 \%\end{aligned}$} & \multicolumn{2}{|c|}{$\begin{aligned} & \frac{370,6}{615,6} \times 100 \% \\
= & 60,2 \%\end{aligned}$} & \multicolumn{2}{|c|}{$\begin{aligned} & \frac{145,6}{615,6} \times 100 \% \\
= & 23,65 \%\end{aligned}$} & \multicolumn{2}{|c|}{$\begin{aligned} & \frac{370,6}{615,6} \times 100 \% \\
= & 60,2 \%\end{aligned}$} \\
\hline
\end{tabular}

Sumber : Hasil Perhitungan.

Tabel 9. Uji Smirnov - Kolmogorov dan Chi - Kuadrat

\begin{tabular}{|l|l|l|l|l|l|l|l|}
\hline \multirow{2}{*}{ No } & Distribusi & \multicolumn{3}{|c|}{ Chi - Kuadrat } & \multicolumn{3}{c|}{ Uji Smirnov - Kolmogorov } \\
\cline { 3 - 8 } & & $x^{2}$ & $x^{2}$ & Keterangan & $\Delta$ maks & $\Delta_{\text {CR }}$ & Keterangan \\
\hline 1 & Normal & 2 & 5,9910 & Diterima & $54,20 \%$ & $56 \%$ & diterima \\
\hline 2 & Log Normal & 0 & 5,9910 & Diterima & $60,20 \%$ & $56 \%$ & Tidak diterima \\
\hline $\mathbf{3}$ & Gumbel & $\mathbf{2}$ & $\mathbf{5 , 9 9 1 0}$ & Diterima & $\mathbf{2 3 , 6 5 \%}$ & $\mathbf{5 6 \%}$ & Diterima \\
\hline 4 & Log Pearson III & 2 & 5,9910 & Diterima & $60,20 \%$ & $56 \%$ & Tidak diterima \\
\hline
\end{tabular}

Sumber : Hasil Perhitungan.

Tabel 10. Perhitungan Koefisien Pengaliran $\left(\mathrm{C}_{\text {rata-rata }}\right)$ Daerah I

\begin{tabular}{|c|c|c|c|c|}
\hline Tata Guna & $\mathrm{Ci}$ & $\begin{array}{c}\mathrm{Ai} \\
(\mathrm{km})^{2}\end{array}$ & $\mathrm{Ci} . \mathrm{Ai}$ & $\mathrm{C}=\frac{\sum_{i=1}^{n} C_{i} A_{i}}{\sum A_{i}}$ \\
\hline Kebun & 0,30 & 0,760 & 0,228 & \multirow[t]{3}{*}{0,315} \\
\hline Padang rumput/semak-semak & 0,60 & 0,040 & 0,024 & \\
\hline$\sum$ & & 0,8 & 0,252 & \\
\hline
\end{tabular}

Sumber: Hasil Perhitungan.

Tabel 11. Perhitungan Koefisien Pengaliran $\left(\mathrm{C}_{\text {rata-rata }}\right)$

\begin{tabular}{|l|l|l|}
\hline \multicolumn{1}{|c|}{ Daerah Pengaliran } & $\mathrm{A}\left(\mathrm{Km}^{2}\right)$ & \multicolumn{1}{c|}{$\mathrm{C}_{\text {rata-rata }}$} \\
\hline Saluran Sekunder 1 & 0,8 & 0,315 \\
\hline Saluran Sekunder 2 & 0,8 & 0,312 \\
\hline Saluran Sekunder 3 & 0,8 & 0,318 \\
\hline Saluran Sekunder 4 & 0,8 & 0,315 \\
\hline Saluran Sekunder 5 & 0,8 & 0,318 \\
\hline
\end{tabular}

Sumber : Hasil Perhitungan

Tabel 12. Nilai Waktu Konsentrasi ( $\left.t_{c}\right)$ untuk Tiap Saluran

\begin{tabular}{|l|l|c|c|c|}
\hline No & \multicolumn{1}{|c|}{ Daerah Pengaliran } & $\mathrm{L}(\mathrm{Km})$ & $\mathrm{S}$ & $\mathrm{T}_{\mathrm{c}}$ (jam) \\
\hline 1 & Saluran Sekunder 1 & 2,00 & 0,00303 & 1,0575 \\
\hline 2 & Saluran Sekunder 2 & 2,00 & 0,00305 & 1,0542 \\
\hline 3 & Saluran Sekunder 3 & 2,00 & 0,00310 & 1,0464 \\
\hline 4 & Saluran Sekunder 4 & 2,00 & 0,00310 & 1,0464 \\
\hline 5 & Saluran Sekunder 5 & 2,00 & 0,00303 & 1,0575 \\
\hline
\end{tabular}

Sumber : Hasil Perhitungan 
Tabel 13. Nilai Intensitas Curah Hujan (I) untuk Tiap Saluran

\begin{tabular}{|c|l|c|c|c|}
\hline No & \multicolumn{1}{|c|}{ Daerah Pengaliran } & $\mathrm{X}_{\mathrm{Tr}}(\mathrm{mm})$ & $\mathrm{T}_{\mathrm{c}}(\mathrm{jam})$ & $\mathrm{I}(\mathrm{mm} / \mathrm{jam})$ \\
\hline 1 & Saluran Sekunder 1 & 495,303 & 1,0575 & 165,430 \\
\hline 2 & Saluran Sekunder 2 & 495,303 & 1,0542 & 165,775 \\
\hline 3 & Saluran Sekunder 3 & 495,303 & 1,0464 & 166,600 \\
\hline 4 & Saluran Sekunder 4 & 495,303 & 1,0464 & 166,600 \\
\hline 5 & Saluran Sekunder 5 & 495,303 & 1,0575 & 165,430 \\
\hline
\end{tabular}

Sumber : Hasil Perhitungan

Tabel 14. Nilai Debit Air Hujan Rencana $\left(Q_{a h}\right)$ untuk Tiap Saluran

\begin{tabular}{|c|l|c|c|c|c|}
\hline No & \multicolumn{1}{|c|}{ Daerah Pengaliran } & C & $\mathrm{I}(\mathrm{mm} / \mathrm{jam})$ & $\mathrm{A}\left(\mathrm{Km}^{2}\right)$ & $\mathrm{Q}_{\text {ah }}\left(\mathrm{m}^{3} / \mathrm{det}\right)$ \\
\hline 1 & Saluran Sekunder 1 & 0,315 & 165,430 & 0,8 & 3,22 \\
\hline 2 & Saluran Sekunder 2 & 0,312 & 165,775 & 0,8 & 3,20 \\
\hline 3 & Saluran Sekunder 3 & 0,318 & 166,600 & 0,8 & 3,30 \\
\hline 4 & Saluran Sekunder 4 & 0,315 & 166,600 & 0,8 & 3,24 \\
\hline 5 & Saluran Sekunder 5 & 0,318 & 165,430 & 0,8 & 3,25 \\
\hline
\end{tabular}

Sumber : Hasil Perhitungan

Tabel 15. Nilai Debit Drainase Rencana Kumulatif $\left(\mathrm{Q}_{\mathrm{r} \text { kum }}\right)$ untuk Tiap Saluran

\begin{tabular}{|c|c|c|c|c|}
\hline No & Saluran & \multicolumn{3}{|c|}{ Debit Drainase Rencana Kumulatif $Q_{\text {r kumulatif }}\left(\mathrm{m}^{3} / \mathrm{dt}\right)$} \\
\hline 1 & Saluran $1\left(\mathrm{Q}_{\mathrm{s} 1}\right)$ & $\mathrm{Q}_{\mathrm{S} 1}$ & 3,22 & 3,22 \\
\hline 2 & Saluran $2\left(\mathrm{Q}_{\mathrm{s} 2}\right)$ & $\mathrm{Q}_{\mathrm{S} 1+} \mathrm{Q}_{\mathrm{S} 2}$ & $3,22+3,20$ & 6,42 \\
\hline 3 & Saluran $3\left(\mathrm{Q}_{\mathrm{s} 3}\right)$ & $\mathrm{Q}_{\mathrm{S} 1}+\mathrm{Q}_{\mathrm{S} 2}+\mathrm{Q}_{\mathrm{S} 3}$ & $3,22+3,20+3,30$ & 9,72 \\
\hline 4 & Saluran $4\left(\mathrm{Q}_{\mathrm{S} 4}\right)$ & $\mathrm{Q}_{\mathrm{r} 3+} \mathrm{Q}_{\mathrm{S} 4}$ & $9,72+3,24$ & 12,96 \\
\hline 5 & Saluran $5\left(\mathrm{Q}_{\mathrm{s} 5}\right)$ & $\mathrm{Q}_{\mathrm{r} 4+} \mathrm{Q}_{\mathrm{S} 5}$ & $12,96+3,25$ & 16,21 \\
\hline
\end{tabular}

Sumber : Hasil Perhitungan

Tabel 16. Kapasitas Drainase Untuk Tiap Saluran

\begin{tabular}{|c|l|c|c|c|c|c|c|c|c|c|c|}
\hline No & Daerah & \multicolumn{3}{|c|}{ Dimensi Eksisting Saluran } & $\mathrm{m}$ & $\mathrm{n}$ & $\begin{array}{c}\mathrm{A} \\
\left(\mathrm{m}^{2}\right)\end{array}$ & $\begin{array}{c}\mathrm{P} \\
(\mathrm{m})\end{array}$ & $\begin{array}{c}\mathrm{R} \\
(\mathrm{m})\end{array}$ & $\begin{array}{c}\mathrm{Q}_{\mathrm{s}} \\
\left(\mathrm{m}^{3} / \mathrm{dt}\right)\end{array}$ \\
\cline { 2 - 12 } & $\mathrm{S}$ & $\mathrm{B}(\mathrm{m})$ & $\mathrm{T}(\mathrm{m})$ & $\mathrm{h}(\mathrm{m})$ & & & & & & & \\
\hline 1 & $\begin{array}{l}\text { Saluran } \\
\text { Sekunder 1 }\end{array}$ & 0,00303 & 2,30 & 6,30 & 1,50 & 2,00 & 0,02 & 7,95 & 7,71 & 1,031 & 22,33 \\
\hline 2 & $\begin{array}{l}\text { Saluran } \\
\text { Sekunder 2 }\end{array}$ & 0,00305 & 2,30 & 6,30 & 1,50 & 2,00 & 0,02 & 7,95 & 7,71 & 1,031 & 22,40 \\
\hline 3 & $\begin{array}{l}\text { Saluran } \\
\text { Sekunder 3 }\end{array}$ & 0,00310 & 2,20 & 6,20 & 1,50 & 2,00 & 0,02 & 7,80 & 7,61 & 1,030 & 22,15 \\
\hline 4 & $\begin{array}{l}\text { Saluran } \\
\text { Sekunder 4 }\end{array}$ & 0,00310 & 2,20 & 6,20 & 1,50 & 2,00 & 0,02 & 7,80 & 7,61 & 1,030 & 22,15 \\
\hline 5 & $\begin{array}{l}\text { Saluran } \\
\text { Sekunder 5 }\end{array}$ & 0,00303 & 2,30 & 6,30 & 1,50 & 2,00 & 0,02 & 7,95 & 7,71 & 1,031 & 22,33 \\
\hline
\end{tabular}

Sumber : Hasil Perhitungan

Tabel 17. Evaluasi Kapasitas Drainase untuk Tiap Saluran

\begin{tabular}{|l|c|r|r|r|l|}
\hline No & Daerah & $\mathrm{Q}_{\mathrm{s}}\left(\mathrm{m}^{3} / \mathrm{det}\right)$ & $\mathrm{Q}_{\mathrm{r}}\left(\mathrm{m}^{3} / \mathrm{det}\right)$ & Selisih $\left(\mathrm{m}^{3} / \mathrm{det}\right)$ & Keterangan \\
\hline 1 & Saluran 1 & 22,33 & 3,22 & 19,11 & Saluran Memadai \\
\hline 2 & Saluran 2 & 22,40 & 6,42 & 15,98 & Saluran Memadai \\
\hline 3 & Saluran 3 & 22,15 & 9,72 & 12,43 & Saluran Memadai \\
\hline 4 & Saluran 4 & 22,15 & 12,96 & 9,19 & Saluran Memadai \\
\hline 5 & Saluran 5 & 22,33 & 16,21 & 6,12 & Saluran Memadai \\
\hline
\end{tabular}

Sumber : Hasil Perhitungan 


\section{PENUTUP}

\section{Kesimpulan}

Besarnya volume debit air pada sistem jaringan irigasi yang dialirkan melalui saluran sekunder umur rencana 5 tahun $\left(\mathrm{X}_{\mathrm{TR}}=5\right.$ Tahun $)$ dengan menggunakan distribusi probalitas Gumbel adalah 495,303 mm. Intensitas curah hujan 165,43 mm/jam. Menormalisasi kapasitas 122 saluran yang berfungsi dan perbaikan 28 saluran yang tidak berfungsi dengan ketinggiaan air 1,50 m untuk menghilangkan kadar asam tanah di sekitar 150 saluran sekunder. perhitungan saluran sekunder, diambil dari perencanaan debit aliran perhitungan yang terbesar yaitu $Q=22,40$ $\mathrm{m}^{3} / \mathrm{dt}>$ Qr (Debit drainase rencana kumulatif $=16,21 \mathrm{~m}^{3} / \mathrm{dt}$ ) $\Rightarrow$ Ok.Dimensi penampang pada 122 saluran sekunder dan perbaikan 28 saluran yang tidak berfungsi itu semua di normalisasi dengan ukuran tabel dibawah ini :

\begin{tabular}{|c|c|c|c|c|c|c|c|c|c|c|c|c|}
\hline \multirow[t]{2}{*}{ No } & \multirow[t]{2}{*}{ Daerah } & \multicolumn{4}{|c|}{ Dimensi Eksisting Saluran } & \multirow[t]{2}{*}{$\mathrm{m}$} & \multirow[t]{2}{*}{$\mathrm{n}$} & \multirow{2}{*}{$\begin{array}{l}\text { A } \\
\left(\mathrm{m}^{2}\right)\end{array}$} & \multirow{2}{*}{$\begin{array}{l}P \\
(\mathrm{~m})\end{array}$} & \multirow{2}{*}{$\begin{array}{l}R \\
(m)\end{array}$} & \multirow{2}{*}{$\begin{array}{l}\mathrm{F} \\
(\mathrm{m})\end{array}$} & \multirow{2}{*}{$\begin{array}{l}\mathrm{Q}_{\mathrm{s}} \\
\left(\mathrm{m}^{3} / \mathrm{dt}\right.\end{array}$} \\
\hline & & $\mathrm{S}$ & $\mathrm{B}(\mathrm{m})$ & $T(m)$ & $h(m)$ & & & & & & & \\
\hline 1 & $\begin{array}{l}\text { Saluran } \\
\text { Sekunder } 5\end{array}$ & 0,00305 & 2,30 & 6,30 & 1,50 & 2,00 & 0,02 & 7,95 & 7,71 & 1,031 & $0,6 \mathrm{~h}$ & 22,40 \\
\hline
\end{tabular}

\section{DAFTAR PUSTAKA}

1. Chow, V.T., 1992. Hidrolika Saluran Terbuka. Erlangga, Jakarta.

2. Departemen Pekerjaan Umum, 1986. Standar Perencanaan Irigasi. Galang Persada. Bandung.

3. Direktorat Jendral Bina Marga, 1990. Petunjuk Desain Drainase Permukaan Jalan. Jakarta.

4. Edwariansyah, 2008. Tugas Akhir, Identifikasi Banjir dan Pengendaliannya pada Sistem Jaringan Drainase Perumahan Bukit Raya di Kota Sampit. Universitas Palangka Raya, Palangka Raya.

5. Firman, M Sahlana, 2005. Tugas Akhir, Studi Evaluasi Sistem Drainase pada Ruas Jalan Mayjen Sungkono Surabaya. Institut Teknologi Nasional, Malang.

6. Hindarko, 2000. Drainase Perkotaan. Es-HA, Yogyakarta.

7. Kamiana, I Made. 1987. Modul Kuliah Hidrologi. Universitas Palangka Raya, Palangka Raya.

8. Notodihardjo, Mardjono. 1998. Drainase Perkotaan. Universitas Tarumanagara, Jakarta.

9. Pusat Penelitian dan Pengembangan Sumber Daya Air, Badan Penelitian dan Pengembangan Kimpraswil, Departemen Pekerjaan Umum, 2002. Kriteria Desain Bangunan Pengendalian Banjir. Pusat Penelitian dan Pengembangan Sumber Daya Air. Bandung.

10. Soemarto , C.D., 1987. Hidrologi Teknik. Usaha Nasional. Surabaya.

11. Soewarno,1995. Aplikasi Metode Statistik Untuk Analisa Data Hidrologi Jilid II. Nova, Bandung.

12. Subarkah, Imam. 1978. Hidrologi Untuk Perencanaan Bangunan Air. Idea Dharma, Bandung.

13. Sunggono, V. 1984. Buku Teknik Sipil. Nova, Bandung.

14. Suripin, 2004. Sistem Drainase Perkotaan Yang Berkelanjutan. Andi, Yogyakarta.

15. Triatmodjo, Bambang. 2008. Hidrologi Terapan. Beta Offset, Yogyakarta.

16. http://www.air.bappenas.go.id 